\title{
Efficiency Trade-Offs in the Design of Competition Policy for the Telecommunications Industry
}

\author{
PHILIP G. GAYLE* \\ Department of Economics, Kansas State University, Manhattan \\ DENNIS L. WEISMAN \\ Department of Economics, Kansas State University, Manhattan
}

\begin{abstract}
Trade-offs between imitation and innovation create natural tensions in the design of competition policy for the telecommunications industry. We explore the relationship between the prices of unbundled network elements (UNEs) and static/dynamic efficiency. We find that even when UNEs are priced to induce efficient make-or-buy decisions from a static perspective, mandatory unbundling reduces the incumbent's incentive to invest from a dynamic perspective. Moreover, while the literature focuses on disincentives for investment in innovation associated with low UNE prices, we find that raising prices for UNEs, when such prices preserve the efficient make-or-buy decision, can discourage investment in process innovation.
\end{abstract}

\section{Introduction}

Trade-offs between imitation and innovation give rise to natural tensions in the design of competition policy for the telecommunications industry. For instance, it is argued that setting low prices for unbundled network elements (UNEs) may encourage entry through resale (imitation) but simultaneously discourage investment in new technologies (innovation). This tension is evident in the 1996 Telecommunications Act, the express purpose of which is:

"To promote competition and reduce regulation in order to secure lower prices and higher quality services for American telecommunications consumers and encourage the rapid deployment of new telecommunications technologies."

A key question for government policymakers concerns whether the focus of competition policy should be on fostering lower prices or on stimulating innovation

\footnotetext{
* Contact author. Department of Economics, Kansas State University, Manhattan, KS 66506-4001, USA. Tel. (785) 532-4581; Fax: (785) 532-6919, Email: gaylep@ksu.edu The authors are grateful to Dale Lehman for helpful discussions, to the editor of this special issue, Jeffrey Bernstein, for his encouragement and constructive suggestions, and to an anonymous referee for constructive suggestions for revision. The authors are solely responsible for any remaining errors.
} 
through increased investment in innovation? What are the necessary implications for policies governing unbundling and resale? ${ }^{1}$ In addition, the discussion regarding innovation in the telecommunications industry has, to date, not clearly distinguished between process and product innovation ${ }^{2}$ nor has it disentangled the effects of mandatory unbundling from the effects associated specifically with the pricing of UNEs.

The primary findings of this analysis are four-fold. First, government policies concerning unbundling and resale in telecommunications are not materially different from similar policies governing copyrights, patents and trademarks (CPT) in the general economy. Second, the Federal Communications Commission (FCC) has recognized the inherent problems associated with an exclusive focus on static efficiency and has taken steps to reverse course. Third, even when UNEs are priced to induce the entrant to make the efficient make-or-buy decision from a static perspective, mandatory unbundling lowers the incumbent's incentive to invest from a dynamic perspective. Fourth, while considerable research has focused on the disincentives for investment in innovation associated with low UNE prices, we show that raising prices for UNEs, for the set of UNE prices that preserve the efficient make-or-buy decision, discourages investment in process innovation.

The format for the remainder of this article is as follows. Trade-offs between static and dynamic efficiency are explored in Section 2. The FCC's policy evolution on the unbundling issue is examined in Section 3. In Section 4, we formally model the entrant's make-or-buy decision, the incumbent's optimal investment choice and examine the implications for the pricing of UNEs. A more general approach to demonstrating the relationship between process innovation and UNE prices is developed in Section 5. Section 6 summarizes the main findings and concludes. The Appendix contains the proofs of selected lemmas and propositions.

\section{Trade-offs between static and dynamic efficiency}

The government's decision regarding the specific network elements to unbundle, at what prices, ${ }^{3}$ and for what duration is not materially different from similar decisions regarding CPT, which are essentially government-created barriers to entry. CPT are granted in order to provide the innovator with the requisite incentives to innovate. At any given point in time, the government could presumably declare all CPT null and void. In the short-run, this would serve to reduce the prices for products and services that previously operated under CPT protections. In the longer run, such actions would serve to reduce the rate of innovation. In other words, as a matter of public policy, we accept transitory distortions in static efficiency, prices in excess of incremental (marginal) cost in order to encourage dynamic efficiency, the optimal investment in innovation over time.

\footnotetext{
${ }^{1}$ See Hausman and Sidak (1999) for a comprehensive analysis of the consumer welfare effects of mandatory unbundling.

${ }^{2}$ Tirole (1988, p.388) makes the following distinction between product and process innovation: Product innovations create new goods and services; process innovations reduce the cost of producing existing products. Tirole also notes that it may not always be possible to draw a clear line between the two types of innovation.

${ }^{3}$ See Armstrong (2002) for a comprehensive survey of the voluminous access pricing literature.
} 


\title{
$2.1 \quad$ Historical perspectives
}

The basic idea that competition policy should not focus exclusively on static efficiency to the exclusion of all other considerations has a long history in the economics literature. For example, more than 50 years ago, Professor Joseph Schumpeter admonished against what he termed the "modus operandi of competition" in which economists focused almost exclusively on price competition. Schumpeter argued that:

"[I]n capitalist reality as distinguished from its textbook picture, it is not that kind of competition which counts, but the competition from the new commodity, the new technology, the new source of supply, the new type of organization ... competition which commands a decisive cost or quality advantage and which strikes not at the margins of the profits and the outputs of the existing firms but at their foundations and their very lives." 4

Professor James Bonbright, a leading authority in the field of public utility regulation similarly underscored the critical importance of dynamic efficiency.

\begin{abstract}
"Under unregulated competition, the price system is supposed to function in two ways with respect to the relationship between the price of the product and the cost of production. In the first place, the rate of output of any commodity will so adjust itself to the demand that the market price will tend to come into accord with production costs. But in the second place, competition will impel rival producers to strive to reduce their own production costs in order to maximize profits and even in order to survive in the struggle for markets. This latter, dynamic effect of competition has been regarded by modern economists as far more important and far more beneficent than any tendency of "atomistic" forms of competition to bring costs and prices into close alignment at any given point of time." 5
\end{abstract}

\section{2 "Optimal" barriers to entry}

The use of CPT as public policy instruments implicitly recognizes that there are so-called Optimal Barriers to Entry. The optimal barrier to entry may be defined as a barrier to entry that maximizes the discounted flow of economic welfare. Whereas barriers to entry may temporarily sustain prices above competitive levels - leading to losses in static efficiency the complete absence of all barriers to entry will tend to discourage investment in innovation - leading to losses in dynamic efficiency. Hence, while barriers to entry can be a source of market power, the complete absence of barriers to entry may constitute the ultimate barrier to entry. Indeed, as Professor Schumpeter observed "perfectly free entry into a new field may make it impossible to enter it at all". ${ }^{6}$

"It is in this sense that competition policies (for example, unbundling and resale) that focus
exclusively on eliminating barriers to entry necessarily entail trade-offs between imitation and
innovation (respectively, between static and dynamic efficiency). To wit, permitting market entrants
to lease UNEs from the incumbent provider at prices that may be unduly favorable to new market
entrants invites those new entrants to become de facto clones of the incumbent provider. ${ }^{7}$ In other
words, this policy decision trades off innovation for imitation. And yet, as Professors Bonbright and

\footnotetext{
${ }^{4}$ Schumpeter (1975, p.84).

${ }^{5}$ Bonbright (1961, p.53).

${ }^{6}$ Schumpeter (1975, pp.104-105).

${ }^{7}$ See, for example, Kahn et al (1999) and Weisman (2000).
} 
Schumpeter remind us, it is principally investment in innovation that drives a market economy and enhances consumer welfare."

\title{
3 Tracing the FCC's policy evolution on network unbundling
}

It is instructive in exploring the trade-offs between imitation and innovation to trace the FCC's policy evolution on the issue of unbundling and the pricing of UNEs because it has changed over time in recognition of inherent flaws with its original approach.

Following the passage of the 1996 Telecommunications Act, the FCC issued its Local Competition Order in August of 1996. In this order, the FCC championed its total long run incremental cost (TELRIC) approach to the pricing of UNEs, ${ }^{8}$ and placed virtually no restrictions on the number and type of network elements that the Incumbent Local Exchange Carriers (ILECs) were required to unbundle. ${ }^{9}$

\subsection{The stepping-stone theory}

The FCC initially perceived that its fundamental charge in implementing the provisions of the 1996 Telecommunications Act was to mandate a competitive market outcome rather than to foster a competitive process ala Professor Schumpeter. ${ }^{10}$ Justice Breyer sought to point out the inherent problems with the FCC's approach:

\begin{abstract}
"The competition that the Act seeks is a process, not an end result; and a regulatory system that imposes through administrative mandate a set of prices that tries to mimic those that competition would have set does not thereby become any less a regulatory process; nor any the more a competitive one." 11
\end{abstract}

For example, in the UNE Remand Order, the FCC clearly took the view that network unbundling would accelerate facilities-based investment on the part of the new entrants. This conclusion was based, in part, on assurances by the Competitive Local Exchange Carriers (CLECs) that they would build their own networks once they established a "foothold" in the market with the use of UNE-P. ${ }^{12,13}$ This has sometimes been referred to as the stepping-stone theory because it was envisioned that the CLECs would transition over time from leasing network elements to building their own facilities-based networks. ${ }^{14}$ The following passage is instructive.

\footnotetext{
${ }^{8}$ The TELRIC standard has also been characterized as the "ideally-efficient firm" standard because it presumes the incumbent provider is ideally efficient in provisioning network elements. See Kahn et al (1999) and Weisman (2000).

${ }^{9} \mathrm{See}$, in particular, FCC $(1996,679)$.

${ }^{10}$ For a critical appraisal of the FCC's "efficient firm" costing standard and the competitive distortions that it creates, see Kahn et al (1999), Lehman and Weisman (2000), and Weisman (2000).

${ }^{11}$ Iowa Utilities Board v. FCC, 525 U.S. 366, 424 (1999).

12 The UNE-Platform ("UNE-P") is a special type of resale in which the network inputs are combined for the entrant by the incumbent provider. The price for UNE-P is lower than that of pure resale because it is based on TELRIC rather than avoided cost, but the two are functionally indistinguishable otherwise.

${ }^{13}$ Hazlett and Havenner (2003, p.447) note that the share price of both the ILECs and telecommunications equipment manufacturers declined upon announcement of the FCC's decision to liberalize unbundling rules.

${ }^{14}$ In an empirical analysis of the determinants of Incumbent Local Exchange Carriers' (ILEC) investment, Jung, Gayle, and Lehman (2007) find that the effect of competiton spurred by mandatory sharing of network elements on ILEC's investment is weak but may be negative for some measures of competition.
} 
"We agree with the competitive LECs that argue that unbundled access to certain incumbents' network elements will accelerate initially competitors' development of alternative networks because it will allow them to acquire sufficient customers and the necessary market information to justify the construction of new facilities. ${ }^{15}$ (footnotes omitted)."

\subsection{A policy "correction"}

The FCC's views as expressed in the subsequent Triennial Review Order concerning the relationship between unbundling and investment in facilities-based networks are an aboutface from its earlier views as expressed in the UNE Remand Order.

"While unbundling can serve to bring competition to markets faster than it might otherwise develop, we are very aware that excessive network unbundling requirements tend to undermine the incentives of both incumbent LECs and new entrants to invest in new facilities and deploy new technology.", 16

Finally, in its TRO on Remand, the FCC continues this line of reasoning when it eliminated mass market switching as an UNE. The following passage is noteworthy:

"Further, regardless of any potential impairment that may still exist, we exercise our "at a minimum authority" and conclude that the disincentives to investment posed by the availability of unbundled switching, in combination with the unbundled loops and shared transport, justify a nationwide bar on such unbundling." 17

In addition to narrowing the scope of unbundling obligations imposed on incumbent providers, the FCC recognized that TELRIC may have discouraged facilities-based entry.

"To the extent that the application of our TELRIC pricing rules distorts our intended pricing signals by understating forward-looking costs, it can thwart one of the central purposes of the Act: the promotion of facilities-based competition." 18

Notably, the FCC's more-balanced approach reflects, in part, the guidance that had previously been provided by the courts. As the DC Circuit explains:

\footnotetext{
"Each unbundling of an element imposes costs of its own, spreading the disincentive to invest in innovation ... At the same time - the plus that the Commission focuses on single-mindedly - a broad mandate can facilitate competition by eliminating the need for separate construction of facilities where such construction would be wasteful. Justice Breyer concluded that fulfillment of the Act's purposes therefore called for 'balance' between these competing concerns." 19 (citations omitted).
}

\footnotetext{
${ }^{15}$ FCC (1999, 112).

${ }^{16}$ FCC (2003. A.3).

${ }^{17} \mathrm{FCC}(2005,204)$.

${ }^{18}$ FCC (2003, B.3)

${ }^{19}$ See United States Telecommunications Association v. FCC, 290 F.3d, 2002 at 427.
} 
The stepping-stone theory argues that CLECs will naturally transition over time from reselling the services of the incumbent providers to investing in their own facilities-based networks. And yet the reality is likely the opposite - the presence of multiple facilitiesbased providers will naturally create the wholesale conditions that regulators seek as each facilities-based provider strives to increase network utilization by reselling its excess capacity. Hence, rather than facilities-based networks being an outgrowth of resale competition, as the stepping-stone theory would suggest, resale competition would actually be an outgrowth of multiple facilities-based networks.

\begin{abstract}
"As discussed in Section 2, Professor Schumpeter cautioned that the complete absence of barriers to entry may well constitute the ultimate barrier to entry and this is likely to be particularly problematic in technologically dynamic industries. Professor Schumpeter's main point will not be lost on the numerous, now-defunct, facility-based CLECs in the U.S. that proceeded to lose billions of dollars when the FCC's introduction of UNE-P along with artificially low prices for network elements resulted in what was essentially ultra-free entry." 20

"The above observations serve to underscore a critical principle of sound competition policy: policies that reward imitation rather than innovation will attract those market entrants adept at imitation, predominantly arbitragers, while driving away genuine innovators.",21 22

"The FCC's “court-prodded" elimination of UNE-P was based on the realization that facilitiesbased entry and associated product differentiation and innovation would be enhanced with the elimination of mass market switching as an UNE. This could be expected to benefit consumers through enhanced dynamic efficiency even if it should result in some softening of price competition in retail markets." 23,24
\end{abstract}

\title{
$4 \quad$ Modeling and analysis
}

In this section, we develop a two-stage game in which the incumbent (ILEC) chooses investment in innovation in the first stage and competes ala Bertrand against a single entrant (CLEC) in the second stage. This model enables us to (1) analyze the entrant's make-or-buy decision, including implications for the pricing of UNEs; and (2) analyze the effect of unbundling requirements on the ILEC's decision to invest in process innovation.

Suppose that the ILEC and the entrant produce differentiated products with symmetric demand functions given, respectively, by $Q_{i}=\alpha-\beta p_{i}+\gamma p_{e}$ and $Q_{e}=\alpha-\beta p_{e}+\gamma p_{i}$, where

\footnotetext{
${ }^{20}$ Kahn (2005, pp.48-49).

${ }^{21}$ Michael Powell, the immediate past chairman of the FCC, commented recently on the boom and bust in telecommunications markets and the regulators' culpability in it. He noted, in particular, that regulators attempted to drive the price of entry close to zero in telecommunications markets and, as a result, succeeded in attracting primarily arbitrageurs. See Telecommunications Reports (2005).

${ }^{22}$ On this score, it is noteworthy that the pervasive entry of cable television providers into telecommunications markets with their "triple play" of voice, broadband and video certainly seems to have accelerated in the United States only after the FCC announced the termination of pervasive network unbundling and further signaled its intent to move toward more rational pricing of network elements. See Tardiff (2007) for a recent examination of the inroads that cable providers have made into the voice telephony market.

${ }^{23}$ FCC $(2005,199)$.

${ }^{24}$ Hazlett (2005, pp.14-17) finds that, contrary to expectations, expansive network unbundling leads to disinvestment in the telecommunications sector. See also Crandall et al (2004).
} 
$\alpha>0$, and $\beta>\gamma>0$. The assumption that $\beta>\gamma>0$ implies that the products are substitutes, differentiated, and own price effects are greater than cross price effects. Variables with the subscript $i$ and $e$ indicate the ILEC and the entrant, respectively.

Each unit of the final good produced $\left(Q_{i}\right.$ or $\left.Q_{e}\right)$ requires one unit of an essential input that may be produced by the incumbent or the entrant. The regulator requires the incumbent to make the input available to the entrant at a per unit price of $w$, but the entrant is under no reciprocal obligation. The entrant may choose to purchase the input from the incumbent at the regulated price or make the input itself.

First, suppose the entrant purchases the input from the incumbent, then the profit functions are given by:

(1) $\Pi_{i}^{B}=\left(p_{i}-c_{i}^{u}-c_{i}^{d}\right)\left(\alpha-\beta p_{i}+\not p_{e}\right)+\left(w-c_{i}^{u}\right)\left(\alpha-\beta p_{e}+\not p_{i}\right)-\delta I$,

(2) $\Pi_{e}^{B}=\left(p_{e}-w-c_{e}^{d}\right)\left(\alpha-\beta p_{e}+\not p_{i}\right)$,

where $\Pi_{i}^{B}$ and $\Pi_{e}^{B}$ are the incumbent's and entrant's profits, $c_{i}^{d}$ and $c_{e}^{d}$ are the incumbent's and entrant's constant marginal cost of downstream production, $c_{i}^{u}$ is the incumbent's marginal cost of the essential upstream input, $I$ is investment by the incumbent on process innovation to produce the essential input more efficiently, while $\delta$ is the constant marginal cost of this investment. We focus on the incumbent's incentive to innovate given that the sharing obligation is asymmetrical. The relationship between investment spending and the marginal cost of the essential input is given by $c_{i}^{u}=c-I^{\frac{1}{2}}$, where $c>0$.

When firms simultaneously choose final product prices to maximize profit, then, in any Bertrand-Nash equilibrium, these prices satisfy the following first-order conditions:

$$
\begin{aligned}
& \text { (3) } \alpha-\beta p_{i}+\not p_{e}+\gamma\left(w-c_{i}^{u}\right)+\beta\left(c_{i}^{d}+c_{i}^{u}-p_{i}\right)=0 \text {, } \\
& \text { (4) } \alpha+\not p_{i}-\beta p_{e}+\beta\left(w+c_{e}^{d}-p_{e}\right)=0 .
\end{aligned}
$$

Lemma 1: Bertrand-Nash equilibrium prices in the case where the entrant buys the essential input from the incumbent are given by:

$$
\begin{aligned}
& \text { (5) } p_{i}=\frac{2 \alpha \beta+\alpha \gamma+3 w \beta \gamma+\beta \gamma c_{e}^{d}-2 \beta \gamma c_{i}^{u}+2 \beta^{2} c_{i}^{d}+2 \beta^{2} c_{i}^{u}}{4 \beta^{2}-\gamma^{2}}, \\
& \text { (6) } p_{e}=\frac{2 \alpha \beta+\alpha \gamma+\beta \gamma c_{i}^{d}+\beta \gamma c_{i}^{u}+2 w \beta^{2}+w \gamma^{2}+2 \beta^{2} c_{e}^{d}-\gamma^{2} c_{i}^{u}}{4 \beta^{2}-\gamma^{2}} .
\end{aligned}
$$

Proof: Solving (3) and (4) simultaneously yields $p_{i}$ and $p_{e}$.

Now, suppose the entrant decides to make the essential input rather than purchase it from the incumbent. In this case, the profit functions are given by: 
(7) $\Pi_{i}^{M}=\left(p_{i}-c_{i}^{u}-c_{i}^{d}\right)\left(\alpha-\beta p_{i}+\not p_{e}\right)-\delta I$,

(8) $\Pi_{e}^{M}=\left(p_{e}-c_{e}^{u}-c_{e}^{d}\right)\left(\alpha-\beta p_{e}+\gamma p_{i}\right)$,

where $\Pi_{i}^{M}$ and $\Pi_{e}^{M}$ are the incumbent's and entrant's profits, respectively, and $c_{e}^{u}$ is the entrant's marginal cost of making the essential input. In any Bertrand-Nash equilibrium, final product prices satisfy the following first-order conditions:

(9) $\alpha-\beta p_{i}+\not p_{e}+\beta\left(c_{i}^{d}+c_{i}^{u}-p_{i}\right)=0$,

(10) $\alpha+\not p_{i}-\beta p_{e}+\beta\left(c_{e}^{u}+c_{e}^{d}-p_{e}\right)=0$.

Lemma 2: Bertrand-Nash equilibrium prices in the case where the entrant makes the essential input are given by:

$$
\begin{aligned}
& \text { (11) } p_{i}=\frac{2 \alpha \beta+\alpha \gamma+\beta \gamma c_{e}^{d}+\beta \gamma c_{e}^{u}+2 \beta^{2} c_{i}^{d}+2 \beta^{2} c_{i}^{u}}{4 \beta^{2}-\gamma^{2}}, \\
& \text { (12) } p_{e}=\frac{2 \alpha \beta+\alpha \gamma+\beta \gamma c_{i}^{d}+\beta \gamma c_{i}^{u}+2 \beta^{2} c_{e}^{d}+2 \beta^{2} c_{e}^{u}}{4 \beta^{2}-\gamma^{2}} .
\end{aligned}
$$

Proof: Solving (9) and (10) simultaneously yields $p_{i}$ and $p_{e}$.

In the first stage of the game, prior to downstream price competition, the incumbent chooses the level of investment. As such, conditional on optimizing price-setting behavior in the downstream market, the incumbent is able to choose its profit-maximizing level of investment.

Lemma 3: In the case where the entrant buys the essential input from the incumbent, the incumbent's optimal investment choice is given by:

(13)

$$
I^{B}=\left(\begin{array}{l}
2 c \gamma^{5}-8 c \beta^{5}-8 w \beta^{5}-w \gamma^{5}+16 \alpha \beta^{4}+\alpha \gamma^{4}-4 c \beta \gamma^{4}+8 c \beta^{4} \gamma+2 w \beta \gamma^{4}-\alpha \beta \gamma^{3} \\
+8 \alpha \beta^{3} \gamma-8 \beta^{5} c_{i}^{d}+\gamma^{5} c_{i}^{d}-8 \beta^{5} c_{e}^{d}-2 \beta \gamma^{4} c_{i}^{d}+4 \beta^{4} \gamma_{i}^{d}+4 \beta^{4} c_{e}^{d}-6 c \beta^{2} \gamma^{3} \\
+8 c \beta^{3} \gamma^{2}+w \beta^{2} \gamma^{3}+6 w \beta^{3} \gamma^{2}-6 \alpha \beta^{2} \gamma^{2}-3 \beta^{2} \gamma^{3} c_{i}^{d}+8 \beta^{3} \gamma^{2} c_{i}^{d}-2 \beta^{2} \gamma^{3} c_{e}^{d}+6 \beta^{3} \gamma^{2} c_{e}^{d} \\
-8 \beta^{5}+2 \gamma^{5}-4 \beta \gamma^{4}+8 \beta^{4} \gamma+32 \beta^{4} \delta+2 \gamma^{4} \delta-6 \beta^{2} \gamma^{3}+8 \beta^{3} \gamma^{2}-16 \beta^{2} \gamma^{2} \delta
\end{array}\right)
$$

In the case where the entrant makes the essential input, the incumbent's profitmaximizing investment is given by: 
(14)

$$
I^{M}=\left(\begin{array}{c}
4 \alpha \beta^{4}-4 c \beta^{5}-c \beta \gamma^{4}-\alpha \beta \gamma^{3}+2 \alpha \beta^{3} \gamma-4 \beta^{5} c_{i}^{d}-\beta \gamma^{4} c_{i}^{d}+2 \beta^{4} \gamma c_{e}^{d} \\
+2 \beta^{4} \gamma c_{u}^{e}+4 c \beta^{3} \gamma^{2}-2 \alpha \beta^{2} \gamma^{2}+4 \beta^{3} \gamma^{2} c_{i}^{d}-\beta^{2} \gamma^{3} c_{e}^{d}-\beta^{2} \gamma^{3} c_{e}^{u} \\
-4 \beta^{5}-\beta \gamma^{4}+16 \beta^{4} \delta+\gamma^{4} \delta+4 \beta^{3} \gamma^{2}-8 \beta^{2} \gamma^{2} \delta
\end{array}\right)^{2}
$$

Proof: See Appendix.

\subsection{Entrant's make-or-buy decision ${ }^{25}$}

A significant part of the analysis that follows is conducted via numerical simulations due to the complexity of closed-form solutions for the endogenous variables. Sensitivity analysis confirms that the basic relationships illustrated graphically are robust across a wide range of parameter values. The analytical results in Proposition 3 below support this claim for the relationship between profit-maximizing investment spending and input prices. Parameter values are chosen to ensure the existence of a stable Nash equilibrium. ${ }^{26}$ Furthermore, we only consider equilibria in which production levels, prices, investment level and profit levels are strictly positive. Table 1 displays the simulated parameter values.

\begin{tabular}{|c|c|c|c|c|c|c|c|}
\hline$\alpha$ & $\beta$ & $\gamma$ & $c_{i}^{d}$ & $c_{e}^{d}$ & $c$ & $c_{e}^{u}$ & $\delta$ \\
\hline 5 & 2.25 & 2.2 & 0.3 & 0.6 & 8 & 8 & 0.45 \\
\hline
\end{tabular}

\section{Table 1: Simulated Parameter Values}

Figure 1 displays the relationship between the entrant's profit and the price of the essential input $(w)$ in the case where the entrant buys the input from the incumbent and in the case where the entrant makes the input.

A number of observations are instructive. First, the lowest input price at which a Nash equilibrium exists is $32.21 .^{27}$ Second, the $\Pi_{e}^{B}$ curve is downward sloping and intersects the horizontal $\Pi_{e}^{M}$ curve at an input price of 40.4. This implies that the entrant obtains a higher profit from buying the input from the incumbent rather than making it whenever the price is below 40.4. Third, the entrant would rather make the input than buy it from the incumbent when the input price rises above 40.4 .

\footnotetext{
${ }^{25}$ See Sappington (2005), Borreau and Pinar (2006), and Gayle and Weisman (2007) for formal analyses of the entrant's make-or-buy decision.

${ }^{26}$ A stable Nash equilibrium requires that $\left|\frac{\partial p_{i}}{\partial p_{e}}\right|<1$. Using equation (3), it can be shown that $\frac{\partial p_{i}}{\partial p_{e}}=\frac{\gamma}{2 \beta}$.

${ }^{27}$ Any input price below 32.21 results in a negative marginal cost of producing the upstream input, that is, $c_{i}^{u}=c-I^{\frac{1}{2}}<0$.
} 


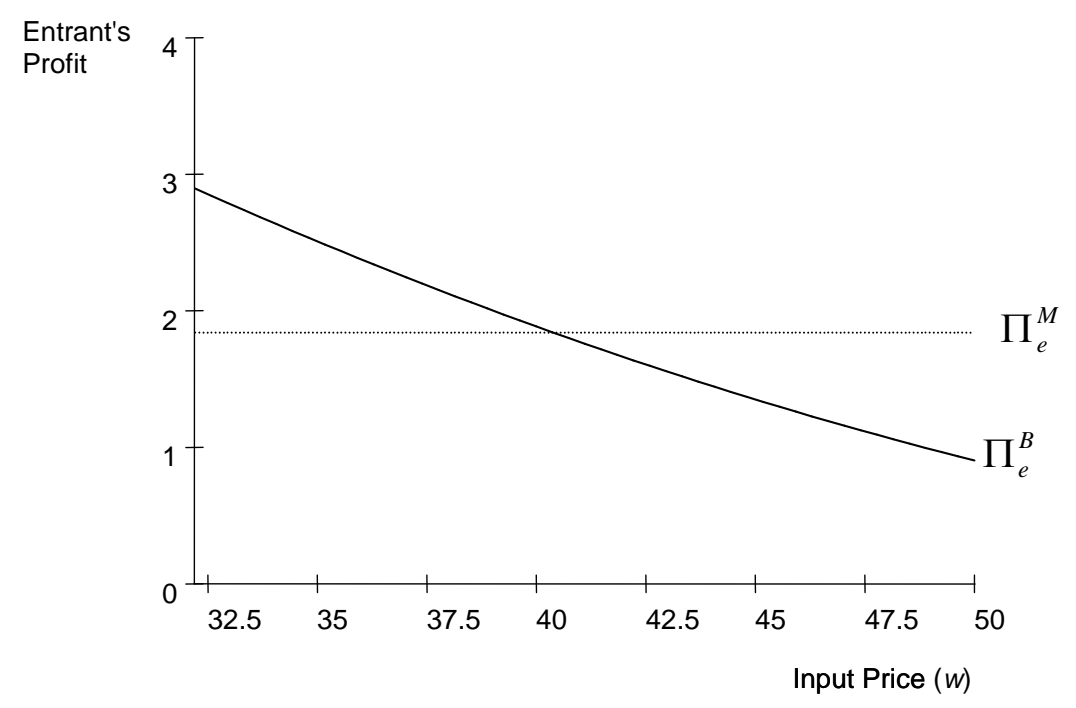

Figure 1: Relationship between entrant's profit and input price.

The parameter values in Table 1 posit that the entrant is less efficient at making the input compared to the incumbent since $c=8, c_{e}^{u}=8$, and $c_{i}^{u}=c-I^{\frac{1}{2}}$, that is, $c_{e}^{u}>c_{i}^{u}$. This implies that, from a static perspective, it is socially optimal for the entrant to purchase the input rather than make it. Therefore, the efficient make-or-buy decision only occurs when the regulator sets $w$ at or below 40.4. An input price above 40.4 results in the entrant making the input even though it does so less efficiently than the incumbent.

\subsection{Incumbent's incentive to invest}

We use the same set of parameter values as in Table 1 to produce Figure 2, which illustrates the relationship between the incumbent's profit-maximizing investment choice and the regulated input price $(w)$. To illustrate the effects of unbundling, we place the incumbent's investment curve when the entrant makes the input $\left(I^{M}\right)$ and the incumbent's investment curve when the entrant buys the input $\left(I^{B}\right)$ on the same graph. 


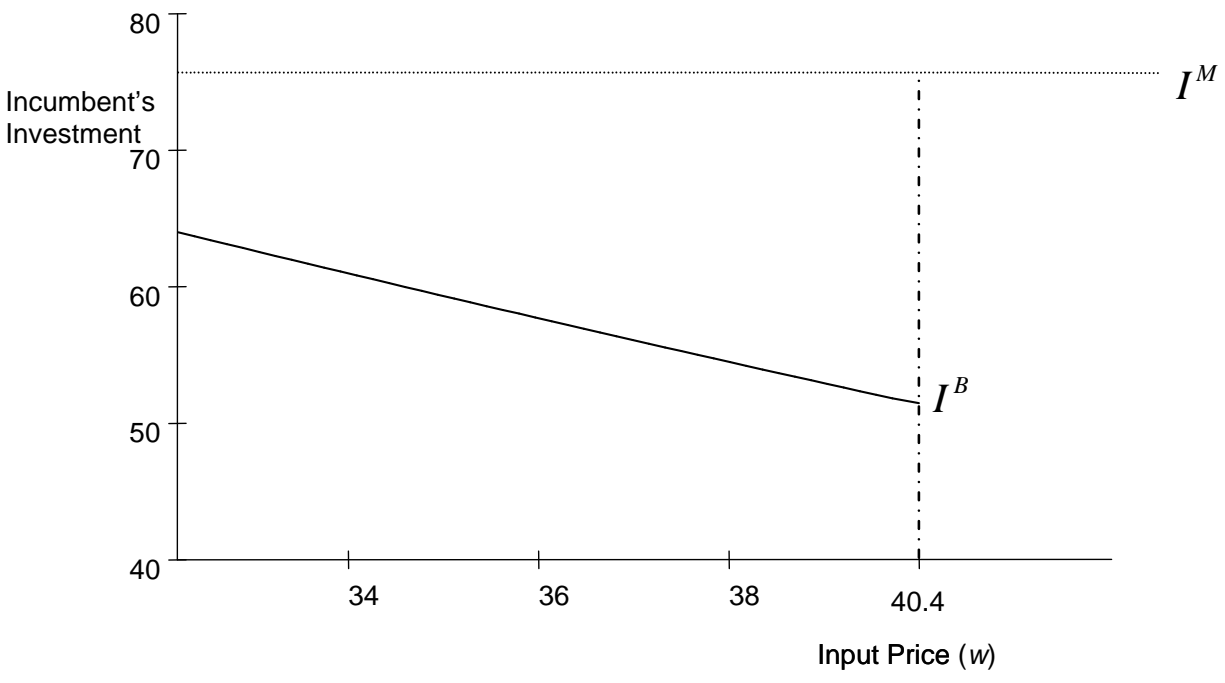

\section{Figure 2: Relationship between incumbent's optimal investment and input price.}

Recall that Figure 1 indicates that the entrant will buy the input rather than make it for any input price between 32.21 and 40.4. Hence, once the regulator mandates unbundling and sets an input price within this range, the incumbent will use the $I^{B}$ curve instead of the $I^{M}$ curve to choose its profit-maximizing level of investment. Notably, the $I^{B}$ curve is always below the $I^{M}$ curve within the relevant input price range. This implies that even when the regulator chooses an input price that induces the entrant to make the efficient make-or-buy decision from a static perspective, unbundling reduces the incumbent's incentive to invest from a dynamic perspective. Hence, in order to induce the incumbent to markedly increase its investment in innovation, the regulator must raise the UNE price above 40.4 but doing so distorts the entrant's efficient build-or-buy decision. ${ }^{28}$ This result embodies the Schumpeterian trade-off between static and dynamic efficiency discussed above.

A common claim in the literature is that low input prices discourage the incumbent from investing in innovation. ${ }^{29}$ However, Figure 2 illustrates that the $I^{B}$ curve is negatively sloped in the relevant input price range. That is, lower input prices marginally increase investment in innovation within the range of prices that preserve the efficient make-or-buy decision. The economic intuition underlying this finding is based on what is referred to in the literature as the Arrow Effect, following Arrow (1962). The incentive to invest in cost-reducing (process) innovation is increasing with the firm's output, ceteris paribus. Since output is decreasing with price and price is increasing with the UNE price $(w)$, it follows that investment in cost-reducing innovation is decreasing in $w$, ceteris paribus.

\footnotetext{
${ }^{28}$ An input price above 40.4 essentially negates the unbundling policy because the entrant would never rationally choose to purchase the input from the incumbent for an input price in this range.

${ }^{29}$ See, for example, Crandall et al (2004), Hazlett and Havenner (2003), Hazlett (2005), Kahn et al (1999); and Weisman (2000).
} 
This analysis further reveals that it is the policy decision to mandate unbundling rather than the low input prices per se that is responsible for reducing the incumbent's incentive to invest. It is therefore important that future policy debates clearly distinguish between the investment effect of unbundling and the investment effect of changes in the UNE price, particularly as it relates to process innovation.

\section{$5 \quad$ A more general approach}

We now demonstrate that the inverse relationship between incumbent's investment and the input price is more general than the simulated relationship illustrated in Figure 2, which is based on specific parameter values. The incumbent chooses its profit-maximizing level of investment by solving the following problem:

(15) $\operatorname{Max}_{I} \Pi_{i}^{B}=\pi_{D}(I)+\pi_{U}(I)-\delta I$,

where $\pi_{D}(I)$ represents the incumbent's reduced-form downstream profit function and $\pi_{U}(I)$ represents the incumbent's reduced-form upstream profit function. The corresponding, necessary first-order condition is:

(16) $\frac{\partial \pi_{D}(I)}{\partial I}+\frac{\partial \pi_{U}(I)}{\partial I}-\delta=0$,

where $\frac{\partial \pi_{D}(I)}{\partial I}+\frac{\partial \pi_{U}(I)}{\partial I}$ is the incumbent's net marginal benefit of investment. We refer to $\frac{\partial \pi_{D}(I)}{\partial I}+\frac{\partial \pi_{U}(I)}{\partial I}$ as net because it contains both positive and negative components as illustrated in the following two equations along with Lemma 4.

(17) $\frac{\partial \pi_{D}(I)}{\partial I}=\left(p_{i}-c_{i}^{u}-c_{i}^{d}\right) \frac{\partial Q_{i}}{\partial I}+Q_{i} \frac{\partial\left(p_{i}-c_{i}^{u}-c_{i}^{d}\right)}{\partial I}$,

(18) $\frac{\partial \pi_{U}(I)}{\partial I}=\left(w-c_{i}^{u}\right) \frac{\partial Q_{e}}{\partial I}+Q_{e} \frac{\partial\left(w-c_{i}^{u}\right)}{\partial I}$.

Lemma 4: For the model specified in (1), $\frac{\partial Q_{i}}{\partial I}>0, \frac{\partial Q_{e}}{\partial I}<0, \frac{\partial\left(p_{i}-c_{i}^{u}-c_{i}^{d}\right)}{\partial I}>0$, and $\frac{\partial\left(w-c_{i}^{u}\right)}{\partial I}>0$ when $\beta>\gamma$.

Proof: See Appendix.

Lemma 4 indicates that an increase in the incumbent's investment increases its production level but decreases the entrant's production level as long as the own price effect 
$(\beta)$ exceeds the cross price effect $(\gamma){ }^{30}$ This occurs because even though an increase in investment reduces the equilibrium price of both firms, it reduces the incumbent's equilibrium price by more. Second, an increase in the incumbent's investment increases both its downstream and upstream markups. The downstream markup increases because an increase in investment lowers upstream marginal cost $\left(c_{i}^{u}\right)$ more than it lowers the incumbent's equilibrium price $\left(p_{i}\right)$, while the upstream markup increases because an increase in investment lowers upstream marginal cost while leaving the regulated input price unchanged.

To understand how a change in input price affects the optimal investment choice, we must analyze how a change in input price affects the net marginal benefit of investment. That is, we must compute and interpret $\frac{\partial^{2} \pi_{D}(I)}{\partial I \partial w}+\frac{\partial^{2} \pi_{U}(I)}{\partial I \partial w}$.

Using the model above along with equations (17) and (18), it is straightforward to show that:

(19) $\frac{\partial^{2} \pi_{D}(I)}{\partial I \partial w}=\frac{\partial\left(p_{i}-c_{i}^{u}-c_{i}^{d}\right)}{\partial w} \frac{\partial Q_{i}}{\partial I}+\frac{\partial Q_{i}}{\partial w} \frac{\partial\left(p_{i}-c_{i}^{u}-c_{i}^{d}\right)}{\partial I}$,

(20) $\frac{\partial^{2} \pi_{U}(I)}{\partial I \partial w}=\frac{\partial\left(w-c_{i}^{u}\right)}{\partial w} \frac{\partial Q_{e}}{\partial I}+\frac{\partial Q_{e}}{\partial w} \frac{\partial\left(w-c_{i}^{u}\right)}{\partial I}$.

In (19), $\frac{\partial\left(p_{i}-c_{i}^{u}-c_{i}^{d}\right)}{\partial w} \frac{\partial Q_{i}}{\partial I}$ indicates how a change in $w$ affects the downstream net marginal benefit of investment via the downstream markup, while $\frac{\partial Q_{i}}{\partial w} \frac{\partial\left(p_{i}-c_{i}^{u}-c_{i}^{d}\right)}{\partial I}$ indicates how a change in $w$ affects the downstream net marginal benefit of investment via the incumbent's production level. In (20), $\frac{\partial\left(w-c_{i}^{u}\right)}{\partial w} \frac{\partial Q_{e}}{\partial I}$ indicates how a change in input price affects the upstream net marginal benefit of investment via the upstream markup, while $\frac{\partial Q_{e}}{\partial w} \frac{\partial\left(w-c_{i}^{u}\right)}{\partial I}$ indicates how a change in input price affects the upstream net marginal benefit of investment via the entrant's demand for the input. The signs of the marginal effects just described are summarized in Proposition 1.

Proposition 1: For the model specified above, $\frac{\partial\left(p_{i}-c_{i}^{u}-c_{i}^{d}\right)}{\partial w} \frac{\partial Q_{i}}{\partial I}>0$, $\frac{\partial Q_{i}}{\partial w} \frac{\partial\left(p_{i}-c_{i}^{u}-c_{i}^{d}\right)}{\partial I}<0, \frac{\partial\left(w-c_{i}^{u}\right)}{\partial w} \frac{\partial Q_{e}}{\partial I}<0$, and $\frac{\partial Q_{e}}{\partial w} \frac{\partial\left(w-c_{i}^{u}\right)}{\partial I}<0$ when $\beta>\gamma$.

Proof: See Appendix.

${ }^{30} \beta$ and $\gamma$ are the own price and cross price coefficients, respectively, in each demand function. 
Proposition 1 implies that the upstream net marginal benefit of investment is unambiguously decreasing in $w$. From Lemma 4 and (18), we know that $\left(w-c_{i}^{u}\right) \frac{\partial Q_{e}}{\partial I}$ is a negative component of the net marginal benefit of investment since the entrant's production level and, by extension its demand for the input, is decreasing in the incumbent's investment. An increase in the input price increases the upstream markup, $\frac{\partial\left(w-c_{i}^{u}\right)}{\partial w}>0$, which serves to increase the negative component of the net marginal benefit of investment. In addition, from Lemma 4 and (18), we know that $Q_{e} \frac{\partial\left(w-c_{i}^{u}\right)}{\partial I}$ is a positive component of the net marginal benefit of investment. An increase in the input price reduces this net marginal benefit component by reducing the entrant's demand for the input $\left(\frac{\partial Q_{e}}{\partial w}<0\right)$.

Notably, Proposition 1 also implies that the effect of changing $w$ on the downstream net marginal benefit of investment is ambiguous. The ambiguity derives from the fact that an increase in $w$ increases the downstream net marginal benefit of investment via increasing the downstream markup, $\frac{\partial\left(p_{i}-c_{i}^{u}-c_{i}^{d}\right)}{\partial w} \frac{\partial Q_{i}}{\partial I}>0$, but simultaneously decreases the downstream net marginal benefit of investment via reducing the incumbent's production level, $\frac{\partial Q_{i}}{\partial w} \frac{\partial\left(p_{i}-c_{i}^{u}-c_{i}^{d}\right)}{\partial I}<0$. An increase in $w$ increases the incumbent's downstream markup because its equilibrium price is increasing in the input price, or $\frac{\partial p_{i}}{\partial w}>0$. The incumbent's production level is decreasing in $w\left(\frac{\partial Q_{i}}{\partial w}<0\right)$ because $\left|\frac{\partial Q_{i}}{\partial p_{i}} \frac{\partial p_{i}}{\partial w}\right|>\left|\frac{\partial Q_{i}}{\partial p_{e}} \frac{\partial p_{e}}{\partial w}\right|$. In summary, the overall effect of a change in $w$ on the downstream net marginal benefit of investment depends on whether the markup effect, $\frac{\partial\left(p_{i}-c_{i}^{u}-c_{i}^{d}\right)}{\partial w} \frac{\partial Q_{i}}{\partial I}$, dominates the production effect, $\frac{\partial Q_{i}}{\partial w} \frac{\partial\left(p_{i}-c_{i}^{u}-c_{i}^{d}\right)}{\partial I}$.

Proposition 2: Assuming that $\beta>\gamma$, then $\frac{\partial^{2} \pi_{D}(I)}{\partial I \partial w}<0$ whenever $\beta$ is sufficiently close to $\gamma$, but $\frac{\partial^{2} \pi_{D}(I)}{\partial I \partial w}>0$ otherwise.

\section{Proof: See Appendix.}

Proposition 2 implies that the overall effect of a change in $w$ on the downstream net marginal benefit of investment is negative when $\beta-\gamma$ is "small" and conversely. Since a change in $w$ may have countervailing effects on the upstream and downstream net marginal benefits of investment, the net optimal investment response of an incumbent to a change in 
$w$ depends on whether changes in the upstream net marginal benefit dominate changes in the downstream net marginal benefit. This suggests Proposition 3.

Proposition 3: In the model specified above, as long as $\beta>\gamma$, changes in the upstream net marginal benefit of investment dominate changes in the downstream net marginal benefit of investment, yielding an inverse relationship between input price and optimal investment spending.

\section{Proof: See Appendix.}

Proposition 3 reveals that the overall net marginal benefit of investment is decreasing in the input price when $\beta>\gamma$. In other words, the negative relationship between input price and the incumbent's profit-maximizing investment spending illustrated in Figure 2 is preserved under any combination of parameter values yielding a stable Nash equilibrium when the own price effect $(\beta)$ exceeds the cross price effect $(\gamma){ }^{31}$

\section{$6 \quad$ Summary and conclusions}

The passage of the 1996 Telecommunication Act was a watershed event in the history of the U.S. Telecommunications Industry. For the first time, incumbent providers were required by law to share their networks with rivals under terms and conditions set by policymakers. This was a controversial industrial policy from the outset as the U.S. Supreme Court weighed in twice regarding the Act's implementation and the decisions rendered by lower courts are seemingly too numerous to count.

At the crux of the debate over the Act's implementation was the trade-off between static and dynamic efficiency. Setting low prices for UNEs may enhance competition today but perhaps at the cost of reduced investment in innovation tomorrow. Regulators were charged with implementing the Act in a manner that struck the appropriate balance but the Act itself provided little clear guidance. ${ }^{32}$

With respect to process innovation, in particular, we find that investment in innovation increases when the unbundling obligation is relaxed. Furthermore, investment in process innovation is shown to be a decreasing rather than an increasing function of UNE prices when such prices preserve the entrant's efficient make-or-buy decision. The foundation for this result is the well-known Arrow Effect.

Finally, our findings suggest that it is the policy decision to mandate unbundling rather than low UNE prices per se that discourage the incumbent's investment in process

\footnotetext{
${ }^{31}$ As mentioned in footnote 28 above, a stable Nash equilibrium requires that $\left|\frac{\partial p_{i}}{\partial p_{e}}\right|<1$. Since $\frac{\partial p_{i}}{\partial p_{e}}=\frac{\gamma}{2 \beta}$ from equation (3), a sufficient condition for stability is $\beta>\gamma$. However, it is possible to have $\left|\frac{\partial p_{i}}{\partial p_{e}}\right|<1$ when $\beta<\gamma$ providing that $\beta$ is not sufficiently smaller than $\gamma$.

${ }^{32}$ Indeed, as Justice Scalia observed in his dissent in AT\&T Corp. v. Iowa Utilities Bd., the 1996 Act "is not a model of clarity. It is in many important respects a model of ambiguity or indeed even self contradiction". AT\&T v. Iowa Utilities Bd. 535 U.S. 366, 397 (1999).
} 
innovation. It is therefore important that future policy debates clearly distinguish between the investment effect of mandatory unbundling and the investment effect associated with changes in UNE prices. Interesting directions for future research include examining the relationship between investment in product innovation and UNE prices to determine whether the tradeoffs we have identified herein hold more generally.

\section{$7 \quad$ References}

Armstrong, Mark (2002) "The Theory of Access Pricing and Interconnection," in Summit M. Majumdar and Ingo Vogelsang (ed.), Handbook of Telecommunications Economics, North-Holland: Amsterdam: 295-384.

Arrow, Kenneth (1962) "Economic Welfare and the Allocation of Resources for Inventions," in R. Nelson (ed.), The Rate and Direction of Inventive Activity, Princeton University Press: Princeton N.J.: 609-625.

Bonbright, James C. (1961) Principles of Public Utility Rates. Columbia University Press: New York.

Borreau, Marc and Dogan, Pinar (2006) "'Build-or-Buy' Strategies in the Local Loop," The American Economic Review Papers and Proceedings, 96: 72-76.

Crandall, Robert W., Allan T. Ingraham and Hal J. Singer (2004) "Do Unbundling Policies Discourage CLEC Facilities-Based Investment," The B.E. Journals in Economic Analysis and Policy, Manuscript 1136, 4: 1-25.

FCC (1996) Implementation of the Local Competition Provisions in the Telecommunications Act of 1996, CC Docket 96-98, First Report and Order, FCC 96-325, Released August 8.

FCC (1999) In the Matter of Implementation of the Local Competition Provisions of the Telecommunications Act of 1996, CC Docket 96-98, Third Report and Order and Fourth Notice of Proposed Rulemaking, Released November 5. (UNE Remand Order).

FCC (2003) In the Matter of Review of the Section 251 Unbundling Obligations of Incumbent Local Exchange Carriers (CC Docket No. 01-338) Report and Order and Order on Remand and Further Notice of Proposed Rulemaking, Released August 21. (Triennial Review Order).

FCC (2003) In the Matter of the Commission's Rules Regarding the Pricing of Unbundled Network Elements and the Resale of Service by Incumbent Local Exchange Carriers, WC Docket No. 03-173, Notice of Proposed Rulemaking, Released September 15.

FCC (2005) In the Matter of Review of the Section 251 Unbundling Obligations of Incumbent Local Exchange Carriers (CC Docket No. 01-338), Released February 4. (Triennial Review Order on Remand). 
Gayle, Philip G. and Dennis L. Weisman (2007) “Are Input Prices Irrelevant for Make-orBuy Decisions?” forthcoming, Journal of Regulatory Economics.

Hausman, Jerry A. and J. Gregory Sidak (1999) "A Consumer-Welfare Approach to Mandatory Unbundling of Telecommunications Networks," Yale Law Journal, 109: 417505.

Hazlett, Thomas W. and Arthur M. Havenner (2003) "The Arbitrage Mirage: Regulated Access Prices with Free Entry in Local Telecommunications Markets," The Review of Network Economics, 2: 440-450.

Hazlett, Thomas W. (2005) "Rivalrous Telecommunications Networks With and Without Mandatory Network Sharing," AEI-Brookings Joint Center for Regulatory Studies, Working Paper 05-07, March.

Jung, Inung, Philip G. Gayle, and Dale Lehman (2007) "Competition \& Investment in Telecommunications," forthcoming, Applied Economics.

Kahn, Alfred E. (2005) "Reforming the FCC and Its Mission: Lessons from the Airline Experience," a paper presented at the Silicon Flatirons Conference, The Digital Broadband Migration: Rewriting the Telecom Act, in Boulder, Colorado, February 14, Journal on Telecommunications and High Technology Law, 4: 44-58.

Kahn, Alfred E., Timothy J. Tardiff and Dennis L. Weisman (1999) "The 1996 Telecommunications Act at Three Years: An Economic Evaluation of Its Implementation by The FCC," Information Economics and Policy, 11: 319-365.

Lehman, Dale E. and Dennis L. Weisman (2000) The Telecommunications Act of 1996: The "Costs" of Managed Competition. Kluwer: Boston.

Sappington, David E. M. (2005) "On the Irrelevance of Input Prices for Make-or-Buy Decisions," American Economic Review, 95: 1631-1638.

Schumpeter, Joseph A. (1975) Capitalism, Socialism and Democracy. Harper Torchbooks: Location of publisher.

Telecommunications Act (1996) Pub. L. No. 104-104, 110 Stat. 56 (codified as amended in scattered sections of 47 U.S.C.)

Timothy J. Tardiff (2007) "Changes in Industry Structure and Technological Convergence: Implications for Competition Policy and Regulation in Telecommunications," forthcoming, International Economics and Economic Policy.

Telecommunications Reports, "Powell Recommends Simplicity in New Law for IP Services.” April 1, 2005.

Tirole, Jean (1988) The Theory of Industrial Organization. MIT Press: Cambridge, MA.

United States Telecommunications Association v. FCC, 290 F.3d. (D.C. Circuit 2002). 
Weisman, Dennis L. (2000) "The (In)Efficiency of the 'Efficient-Firm' Cost Standard," The Antitrust Bulletin, XLV: 195-211.

Weisman, Dennis L. (2002) "Did the High Court Reach An Economic Low in Verizon v. FCC?" The Review of Network Economics, 1: 90-105.

\section{$8 \quad$ Appendix}

This appendix contains the proofs for Lemmas 3 and 4 and Propositions 1, 2 and 3.

\section{Proof of Lemma 3:}

To derive the investment function, we first derive the incumbent's reduced-form profit function by substituting the Nash solutions for product prices into the profit function. Having derived the incumbent's reduced-form profit function, we then differentiate it with respect to investment, set the derivative equal to zero, and use the resulting equation to solve for investment.

In the case where the entrant buys the input from the incumbent, the incumbent's reduced-form profit function is,

(A1) $\Pi_{i}^{B}(I)=\left(\frac{2 \alpha \beta+\alpha \gamma+3 w \beta \gamma+\beta \gamma c_{e}^{d}-2 \beta \gamma\left(c-I^{\frac{1}{2}}\right)+2 \beta^{2} c_{i}^{d}+2 \beta^{2}\left(c-I^{\frac{1}{2}}\right)}{4 \beta^{2}-\gamma^{2}}-\left(c-I^{\frac{1}{2}}\right)-c_{i}^{d}\right)$

$\times\left(\frac{\alpha \beta \gamma+w \gamma^{3}+2 \alpha \beta^{2}-w \beta^{2} \gamma+\left(\beta \gamma^{2}-2 \beta^{3}\right) c_{i}^{d}+\beta^{2} \gamma_{e}^{d}+\left(\beta \gamma^{2}+2 \beta^{2} \gamma-2 \beta^{3}-\gamma^{3}\right)\left(c-I^{\frac{1}{2}}\right)}{(2 \beta+\gamma)(2 \beta-\gamma)}\right)$

$+\left(w-\left(c-I^{\frac{1}{2}}\right)\right)\left(\frac{\beta\left(2 w\left(\beta^{2}-\gamma^{2}\right)-\alpha \gamma-\beta \gamma c_{i}^{d}-2 \alpha \beta+\left(2 \beta^{2}-\gamma^{2}\right) c_{e}^{d}+\left(\gamma^{2}-\beta \gamma\right)\left(c-I^{\frac{1}{2}}\right)\right)}{(2 \beta+\gamma)(2 \beta-\gamma)}\right)-\delta I$

In the case where the entrant makes the input, the incumbent's reduced-form profit function is, 
(A2) $\Pi_{i}^{M}(I)=\left(\frac{2 \alpha \beta+\alpha \gamma+\beta \gamma c_{e}^{d}+\beta \gamma c_{e}^{u}+2 \beta^{2} c_{i}^{d}+2 \beta^{2}\left(c-I^{\frac{1}{2}}\right)}{4 \beta^{2}-\gamma^{2}}-\left(c-I^{\frac{1}{2}}\right)-c_{i}^{d}\right)$

$\times\left(\frac{\beta\left(2 \alpha \beta+\alpha \gamma+\beta \gamma c_{e}^{d}+\beta \gamma c_{e}^{u}+\left(\gamma^{2}-2 \beta^{2}\right) c_{i}^{d}+\left(\gamma^{2}-2 \beta^{2}\right)\left(c-I^{\frac{1}{2}}\right)\right)}{(2 \beta+\gamma)(2 \beta-\gamma)}\right)-\delta I$.

\section{Proof of Lemma 4:}

First, note that $\frac{\partial Q_{i}}{\partial I}=\frac{\partial Q_{i}}{\partial p_{i}} \frac{\partial p_{i}}{\partial I}+\frac{\partial Q_{i}}{\partial p_{e}} \frac{\partial p_{e}}{\partial I}=-\beta \frac{\partial p_{i}}{\partial I}+\gamma \frac{\partial p_{e}}{\partial I} \quad$ and $\frac{\partial Q_{e}}{\partial I}=\frac{\partial Q_{e}}{\partial p_{e}} \frac{\partial p_{e}}{\partial I}+\frac{\partial Q_{e}}{\partial p_{i}} \frac{\partial p_{i}}{\partial I}=-\beta \frac{\partial p_{e}}{\partial I}+\gamma \frac{\partial p_{i}}{\partial I}$. By differentiating the closed-form solutions for prices in (5) and (6) with respect to $I$ and substituting these derivatives into the above expressions for $\frac{\partial Q_{i}}{\partial I}$ and $\frac{\partial Q_{e}}{\partial I}$, we obtain $\frac{\partial Q_{i}}{\partial I}=\left[\frac{\left(2 \beta^{2}-\gamma^{2}\right)(\beta-\gamma)}{2\left(4 \beta^{2}-\gamma^{2}\right)}\right] I^{-\frac{1}{2}}$ and $\frac{\partial Q_{e}}{\partial I}=\left[\frac{\beta \gamma(\gamma-\beta)}{2\left(4 \beta^{2}-\gamma^{2}\right)}\right] I^{-\frac{1}{2}}$. It is obvious that $\frac{\partial Q_{i}}{\partial I}>0$ and $\frac{\partial Q_{e}}{\partial I}<0$ when $\beta>\gamma$.

Second, note that $\frac{\partial\left(p_{i}-c_{i}^{u}-c_{i}^{d}\right)}{\partial I}=\frac{\partial p_{i}}{\partial I}-\frac{\partial c_{i}^{u}}{\partial I}=\left[\frac{2 \beta^{2}+\gamma(2 \beta-\gamma)}{2\left(4 \beta^{2}-\gamma^{2}\right)}\right] I^{-\frac{1}{2}}$. It is obvious that $\left[\frac{2 \beta^{2}+\gamma(2 \beta-\gamma)}{2\left(4 \beta^{2}-\gamma^{2}\right)}\right]>0$ when $\beta>\gamma$. Finally, $\frac{\partial\left(w-c_{i}^{u}\right)}{\partial I}=-\frac{\partial c_{i}^{u}}{\partial I}=\frac{1}{2} I^{-\frac{1}{2}}$.

\section{Proof of Proposition 1:}

First, note that $\frac{\partial\left(p_{i}-c_{i}^{u}-c_{i}^{d}\right)}{\partial w}=\frac{\partial p_{i}}{\partial w}$. Differentiating the closed-form solution for price in (5) with respect to $w$ yields, $\frac{\partial p_{i}}{\partial w}=\frac{3 \beta \gamma}{4 \beta^{2}-\gamma^{2}}>0$ since $\beta>\gamma$. Since $\frac{\partial Q_{i}}{\partial I}>0$ from Lemma 4, it follows that $\frac{\partial\left(p_{i}-c_{i}^{u}-c_{i}^{d}\right)}{\partial w} \frac{\partial Q_{i}}{\partial I}>0$.

Second, note that $\frac{\partial Q_{i}}{\partial w}=\frac{\partial Q_{i}}{\partial p_{i}} \frac{\partial p_{i}}{\partial w}+\frac{\partial Q_{i}}{\partial p_{e}} \frac{\partial p_{e}}{\partial w}=-\beta \frac{\partial p_{i}}{\partial w}+\gamma \frac{\partial p_{e}}{\partial w}$. By differentiating the closed-form solutions for prices in (5) and (6) with respect to $w$, substituting these derivatives into the above expression and rearranging terms, it can be shown that 
$\frac{\partial Q_{i}}{\partial w}=-\beta \frac{\partial p_{i}}{\partial w}+\gamma \frac{\partial p_{e}}{\partial w}=\frac{\gamma\left(\gamma^{2}-\beta^{2}\right)}{4 \beta^{2}-\gamma^{2}}$. This implies that $\frac{\partial Q_{i}}{\partial w}<0 \quad$ when $\beta>\gamma$. Since $\frac{\partial\left(p_{i}-c_{i}^{u}-c_{i}^{d}\right)}{\partial I}>0$ from Lemma 4 , it follows that $\frac{\partial Q_{i}}{\partial w} \frac{\partial\left(p_{i}-c_{i}^{u}-c_{i}^{d}\right)}{\partial I}<0$.

Third, note that $\frac{\partial\left(w-c_{i}^{u}\right)}{\partial w}=1$. Since $\frac{\partial Q_{e}}{\partial I}<0$ from Lemma 4, it follows that $\frac{\partial\left(w-c_{i}^{u}\right)}{\partial w} \frac{\partial Q_{e}}{\partial I}<0$.

Fourth, note that $\frac{\partial Q_{e}}{\partial w}=\frac{\partial Q_{e}}{\partial p_{e}} \frac{\partial p_{e}}{\partial w}+\frac{\partial Q_{e}}{\partial p_{i}} \frac{\partial p_{i}}{\partial w}=-\beta \frac{\partial p_{e}}{\partial w}+\gamma \frac{\partial p_{i}}{\partial w}$. Differentiating the closed-form solutions for prices in (5) and (6) with respect to $w$, substituting these derivatives into the above expression and rearranging terms yields $\frac{\partial Q_{e}}{\partial w}=-\beta \frac{\partial p_{e}}{\partial w}+\gamma \frac{\partial p_{i}}{\partial w}=\frac{2 \beta\left(\gamma^{2}-\beta^{2}\right)}{4 \beta^{2}-\gamma^{2}}$. It follows that $\frac{\partial Q_{e}}{\partial w}<0$ when $\beta>\gamma$. Since $\frac{\partial\left(w-c_{i}^{u}\right)}{\partial I}>0$ from Lemma 4, it follows that $\frac{\partial Q_{e}}{\partial w} \frac{\partial\left(w-c_{i}^{u}\right)}{\partial I}<0$.

\section{Proof of Proposition 2:}

First, note that $\frac{\partial^{2} \pi_{D}(I)}{\partial I \partial w}=\frac{\partial\left(p_{i}-c_{i}^{u}-c_{i}^{d}\right)}{\partial w} \frac{\partial Q_{i}}{\partial I}+\frac{\partial Q_{i}}{\partial w} \frac{\partial\left(p_{i}-c_{i}^{u}-c_{i}^{d}\right)}{\partial I}$. From the proofs of Lemma 4 and Proposition 1, we have closed-form expressions for the right hand side of the above $\quad$ equation: $\quad \frac{\partial\left(p_{i}-c_{i}^{u}-c_{i}^{d}\right)}{\partial w} \frac{\partial Q_{i}}{\partial I}+\frac{\partial Q_{i}}{\partial w} \frac{\partial\left(p_{i}-c_{i}^{u}-c_{i}^{d}\right)}{\partial I}$ $=\left(\frac{3 \beta \gamma}{4 \beta^{2}-\gamma^{2}}\right)\left[\frac{\left(2 \beta^{2}-\gamma^{2}\right)(\beta-\gamma)}{2\left(4 \beta^{2}-\gamma^{2}\right)}\right] I^{-\frac{1}{2}}+\left(\frac{\gamma\left(\gamma^{2}-\beta^{2}\right)}{4 \beta^{2}-\gamma^{2}}\right)\left[\frac{2 \beta^{2}+\gamma(2 \beta-\gamma)}{2\left(4 \beta^{2}-\gamma^{2}\right)}\right] I^{-\frac{1}{2}}$. Factoring and rearranging terms, the right hand side of this expression can be expressed as $\left[\frac{\left[4 \beta^{3}+\gamma^{3}-4 \beta \gamma^{2}-4 \beta^{2} \gamma\right](\beta-\gamma) \gamma}{2(2 \beta+\gamma)^{2}(\gamma-2 \beta)^{2}}\right] I^{-\frac{1}{2}}$. When $\beta>\gamma$, the sign of the last expression is equal to the sign of $\left[4 \beta^{3}+\gamma^{3}-4 \beta \gamma^{2}-4 \beta^{2} \gamma\right]$, which is negative for $\beta$ sufficiently close to $\gamma$ and conversely.

\section{Proof of Proposition 3:}

First, note that $\frac{\partial^{2} \pi_{U}(I)}{\partial I \partial w}=\frac{\partial\left(w-c_{i}^{u}\right)}{\partial w} \frac{\partial Q_{e}}{\partial I}+\frac{\partial Q_{e}}{\partial w} \frac{\partial\left(w-c_{i}^{u}\right)}{\partial I}$. From the proofs of Lemma 4 and Proposition 1, we have closed-form expressions for the right hand side of the above equation. That is, $\frac{\partial\left(w-c_{i}^{u}\right)}{\partial w} \frac{\partial Q_{e}}{\partial I}+\frac{\partial Q_{e}}{\partial w} \frac{\partial\left(w-c_{i}^{u}\right)}{\partial I}=\left[\frac{\beta \gamma(\gamma-\beta)}{2\left(4 \beta^{2}-\gamma^{2}\right)}\right] I^{-\frac{1}{2}}+\left(\frac{2 \beta\left(\gamma^{2}-\beta^{2}\right)}{4 \beta^{2}-\gamma^{2}}\right) \frac{1}{2} I^{-\frac{1}{2}}$. By factoring and rearranging terms, the right hand side of the equation can be written as $\left[\frac{\beta(2 \beta+3 \gamma)(\gamma-\beta)}{2(2 \beta+\gamma)(2 \beta-\gamma)}\right] I^{-\frac{1}{2}}$. From the proof of Proposition 2, we know that 
$\frac{\partial^{2} \pi_{D}(I)}{\partial \mathrm{I} \partial \mathrm{w}}=\left[\frac{\left[4 \beta^{3}+\gamma^{3}-4 \beta \gamma^{2}-4 \beta^{2} \gamma\right](\beta-\gamma) \gamma}{2(2 \beta+\gamma)^{2}(\gamma-2 \beta)^{2}}\right] I^{-\frac{1}{2}} . \quad$ Therefore, $\quad \frac{\partial^{2} \pi_{D}(I)}{\partial \mathrm{I} \partial \mathrm{w}}+\frac{\partial^{2} \pi_{U}(I)}{\partial \mathrm{I} \partial \mathrm{w}}=$ $\left[\frac{\left[4 \beta^{3}+\gamma^{3}-4 \beta \gamma^{2}-4 \beta^{2} \gamma\right](\beta-\gamma) \gamma}{2(2 \beta+\gamma)^{2}(\gamma-2 \beta)^{2}}\right] I^{-\frac{1}{2}}+\left[\frac{\beta(2 \beta+3 \gamma)(\gamma-\beta)}{2(2 \beta+\gamma)(2 \beta-\gamma)}\right] I^{-\frac{1}{2}}$. By factoring and rearranging terms, the right hand side of the last equation can be written as: $\left[\frac{\left[\gamma^{2}(\gamma-2 \beta)-8 \beta^{3}\right](\beta+\gamma)(\beta-\gamma)}{2(2 \beta+\gamma)^{2}(\gamma-2 \beta)^{2}}\right] I^{-\frac{1}{2}}$. When $\beta>\gamma$, the sign of the last expression is equal to the sign of $\left[\gamma^{2}(\gamma-2 \beta)-8 \beta^{3}\right]$, which is always negative. Therefore, $\frac{\partial^{2} \pi_{D}(I)}{\partial I \partial w}+\frac{\partial^{2} \pi_{U}(I)}{\partial I \partial w}<0$ when $\beta>\gamma$. 